\title{
Chemical Composition of Aerosols of an Electronic Cigarette
}

Aerosol and Air Quality Research

\author{
Wen-Hsi Cheng ${ }^{*}$, Chia-Yu Chang, Yi-Ya Chen, Hui-Wen Su \\ Department of Occupational Safety and Hygiene, Fooyin University, Kaohsiung, Taiwan
}

A needle trap sampler (NTS) packed with 60-80-mesh divinylbenzene (DVB) adsorbent inside a 22-gauge stainless steel needle was used as a micro sampling device to extract chemical compounds in electronic cigarette (e-cigarette) aerosol. The samples were then analyzed using gas chromatography (GC)-mass spectroscopy (MS) to determine the constituents. Based on the experimental results, e-cigarette smokers are exposed to high concentrations of nicotine (146 \pm $51 \mathrm{mg} \mathrm{m}^{-3}$ ) during long sessions. If the e-cigarette liquid leaks though the filter of the cartridge, the user is exposed to even greater quantities $\left(914 \mathrm{mg} \mathrm{m}^{-3}\right)$. However, the secondhand aerosol contains less than $1 \mathrm{mg} \mathrm{m}^{-3}$ of nicotine on average (with $0.43-1.74 \mathrm{mg} \mathrm{m}^{-3}$ being the approximate full range). In addition to nicotine, the airborne emissions from e-cigarettes mainly consist of vegetable glycerin, propylene glycol, and triacetin.

Keywords: Electronic cigarette, E-cigarette liquid, Needle trap samplers, Nicotine, Exposure

\section{INTRODUCTION}

An electronic cigarette (e-cigarette) comprises a cartridge that is filled with e-cigarette liquid (e-liquid), which mainly contains nicotine, propylene glycol (PG), and vegetable glycerin (VG), and a heating element to vaporize the e-liquid. When an e-cigarette is puffed, the microprocessor with a sensor activates the heating element, and nicotine is vaporized and then inhaled by the e-cigarette user. Flavors are added to the e-liquid, mimicking the flavors of combustible cigarettes, fruits, or drinks. A mixture of PG and VG is used as the base to which nicotine and flavors are added (Goniewicz et al., 2013).

E-cigarettes have been extensively used as a nicotine delivery device in the last decades mainly because they were promoted as a smoking cessation tool (DeVito and Krishnan-Sarin, 2018). However, the nicotine content of e-liquids can differ greatly from that advertised. According to the laboratory study by DeVito and Krishnan-Sarin (2018), 40\% brands of e-liquids contain a greater percentage of nicotine than indicated on the label. Hadwiger et al. (2010), Cheah et al. (2012), Goniewicz et al. (2013), and Schober et al. (2014) have also found that some nicotine-free e-liquids contained nicotine.

The nicotine content of aerosol from e-cigarettes depends on the amount of nicotine contained in the e-liquids. The puffing behaviors of e-cigarettes also affect the exposure to nicotine of both e-cigarette users and secondhand smokers (DeVito and Krishnan-Sarin, 2018). Kosmider et al. (2018) studied the puffing behavior over $24 \mathrm{~h}$ of regular e-cigarette users. The total number of puffs and number of puffing sessions over $24 \mathrm{~h}$ vary greatly among individuals, and single-puff volumes also varied. E-cigarette users who take more frequent puffs in an effort to receive levels of nicotine that they previously received from combustible cigarettes (compensatory puffing behavior) have higher exposures to potentially harmful constituents in e-cigarette emissions than combustible cigarette users (Lee et al., 2018). Recent reports on the risks associated with exposure to e-cigarettes smoke have identified different session topography patterns of e-cigarette users, and further work is required to determine the risks of exposure to the constituents of e-cigarette aerosol (Pisinger and Døssing, 2014; Lee et al., 2019). 
Many researchers have studied the behaviors of and risks from e-cigarette aerosol. However, the constituents of the aerosol of an e-cigarette in a long session have seldom been assessed. In this work, the chemical constituents of the aerosol from e-cigarettes are examined using a novel microsampling device called a needle trap sampler (NTS). The exposure of smokers to smoke of e-cigarettes during a long session was assessed herein by sampling and analysis in the laboratory and the exposure of secondhand smokers was examined by pilot plan tests.

\section{METHODS}

\subsection{Identification of E-cigarette Aerosol and Secondhand Exposure Scenarios}

No standardized system currently exists for the generation and sampling of heat-not-burn products and e-cigarettes. The components of e-cigarette aerosols vary with the generation voltage and temperatures that are used to heat the e-liquid by heaters on e-cigarette machines (Farsalinos et al., 2018; Shearston et al., 2019; Kim and An, 2020). Therefore, Kim and An (2020) developed a new e-cigarette smoke-generating system to identify the chemicals in the smoke when e-liquids are heated at various temperatures $\left(25-470^{\circ} \mathrm{C}\right)$. Kim and $\mathrm{An}$ 's air ventilation apparatus was composed of an air compressor and a generator to produce aerosol by vaporizing e-liquids. The air samples were collected in 5-mL glass flasks to analyze their contained carbonyl compounds. Kim and An's experimental setup, which included a core heater device, was designed to examine the effect of temperature on e-liquids, but not to mimic real puffing. To consider the real puff of an e-cigarette with a particular cartridge, one e-cigarette device is used herein to ensure that the e-liquids are heated to the same voltage and temperature during a session.

Fig. 1 presents the experimental setup for gathering smoke from e-cigarettes. An exhaustion pump (110 V AC, $480 \mathrm{~W}$, made in Taiwan; P1 in Fig. 1) was used to simulate human inhalation and the e-cigarette machine was started up when the exhaustion pump started. According to Kosmider et al. (2018) in a study of the puffing behaviors over $24 \mathrm{~h}$ of 15 male adult e-cigarette users, a single-puff duration is $3.0 \pm 1.2 \mathrm{~s}$. Accordingly, Pump P1 was operated for $3 \mathrm{~s}$ to simulate a puff. The e-cigarette heater starts up when an appropriate negative pressure is provided by a user's puff though the filter of the cartridge, and the suction stream that is generated by Pump P1 in $3 \mathrm{~s}$ carried a considerable amount of aerosol, like a human puff. In each puff, NTSs were used to sample gaseous compounds in the glass diffusion tube for $15 \mathrm{~s}$ in the active sampling

(e)

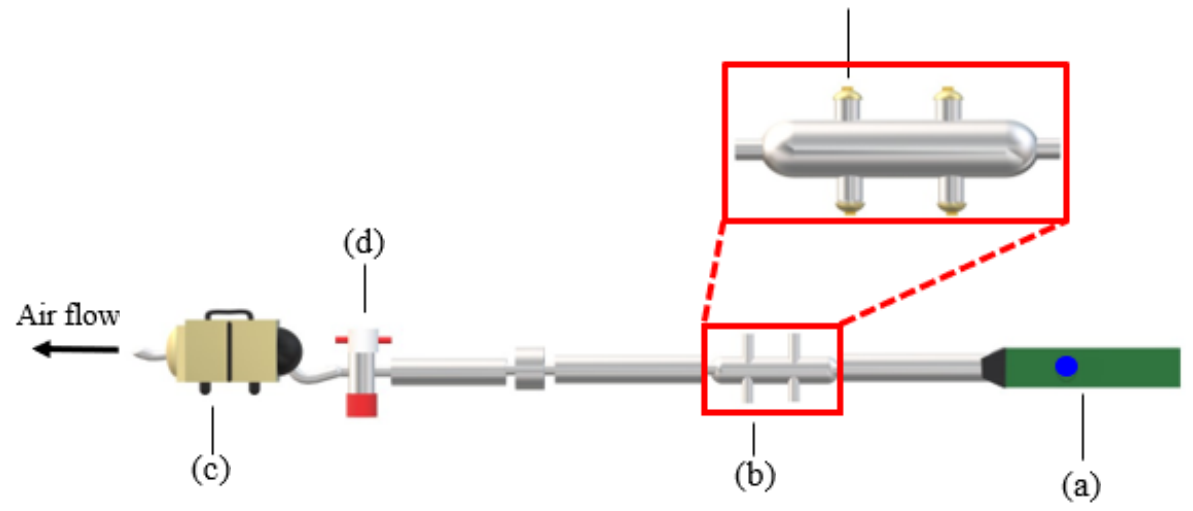

Notes:
(a) Electric cigarette
(b) Diffusion tube
(c) Exhaustion pump (P1)
(d) Control valve
(e) Sampling port

Fig. 1. Experimental setup for sampling chemical compounds in the aerosols of e-cigarettes. 


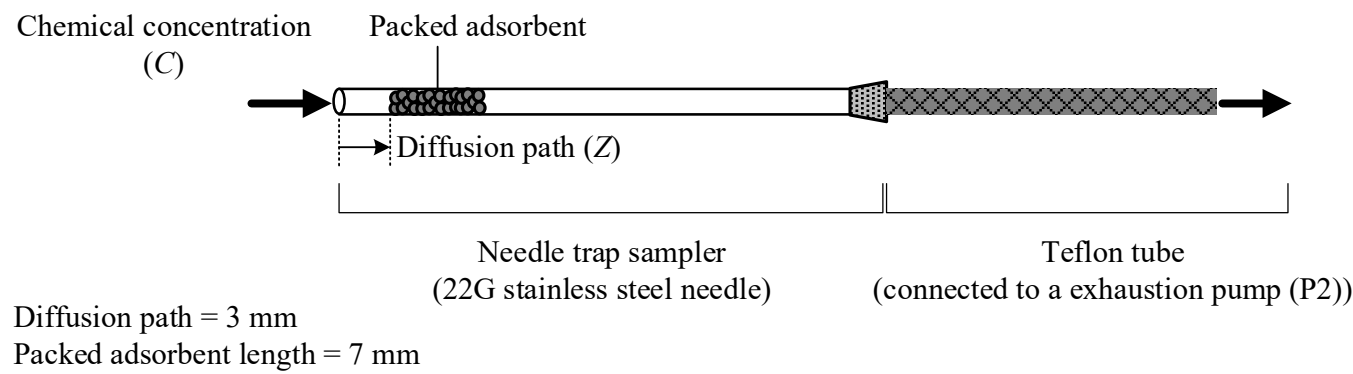

Fig. 2. Schematic configuration of the needle trap sampler.

mode with miniature exhaustion pumps (flow rate $=48 \mathrm{~mL} \mathrm{~min}^{-1}, 6 \mathrm{~V} \mathrm{DC}, 3 \mathrm{~W}$, made in China). Two NTSs were installed though the opposite sampling ports of the diffusion tube to obtain a batch of samples. With the next puff of the e-cigarette, sampling was repeated. The theory of the NTS is presented in detail in the following section.

NTSs were also used to extract emission compounds in e-cigarette aerosol to examine secondhand chemical exposure. Kosmider et al. (2018) measured the puffing topography of 24 e-cigarette users and found that the average number of puffs per single session is $10.2 \pm 7.9$. Hence, the sampling period herein is 10 puffs as an e-cigarette puffing session; each puff was continued for $3 \mathrm{~s}$ and the interval between puffs was $15 \mathrm{~s}$. NTSs were used as a time-weighted average (TWA) sampling tool in a simulation experiment of secondhand aerosol exposure (Fig. 2) to extract the emitted compounds from an e-cigarette in the active sampling mode. To evaluate the performance of an NTS in collecting nicotine in the aerosol, a commonly used air sampler, a solid phase microextraction (SPME) fiber, was also used to sample nicotine in the simulated e-cigarette secondhand puffing scenario. Actually, $100 \mu \mathrm{m}$ polydimethylsiloxane (PDMS) SPME fibers have been used to collect and analyze nicotine in tobacco aerosol for about two decades (Yang and Smetena, 1998; Wu et al., 2002). The sampling site of secondhand aerosols of an e-cigarette was located at the courtyard and corridor in a teaching and research building of a university campus.

\subsection{Preparation of Needle Trap Samplers}

The NTS extracted chemical compounds though a needle by air diffusion. A linear gaseous concentration profile $(C(Z)$ in Fig. 3) was obtained along the diffusion path $(Z)$, and the extraction of the analyte was characterized by the area $(A)$ of the opening of the needle and the length of the diffusion path. Eq. (1) provides the total mass $(n)$ of analyte that was adsorbed in a time interval ( $t$ ) (Lord et al., 2010):

$n=D_{m} \frac{A}{Z} \int C(t) d t$

where $D_{m}$ is the diffusion coefficient of the compound that is adsorbed from the air by the NTS. Therefore, the quantity $(n)$ of the extracted analyte is assumed to be proportional to the mean concentrations of constituent over a sampling time period, $C(t)$.

The NTS, packed with divinylbenzene (DVB) adsorbent with 60-80-mesh diameters, has been used successfully to sample indoor and outdoor air organic compounds (Cheng et al., 2017; Cheng and Wu, 2019; Cheng et al., 2020).

\subsection{Chemicals and Analysis}

The contents of e-liquids and the performance of e-cigarette cartridges are not officially certified in Taiwan. A popular fruit taste, mango, and a single type of cartridge were used in this work. Stainless steel needles $(22 \mathrm{G}$, length $=7 \mathrm{~cm}$, inner diameter $=0.41 \mathrm{~mm}$; Fig. 3 ) were purchased from a local company (Her Ling Co. Ltd., Pingtung, Taiwan) for use in preparing the NTS. Particulate adsorbent DVB were purchased from Supelco (Bellefonte, PA, USA). The chemical compounds in the smoke were collected using an NTS and identified using an Agilent gas 


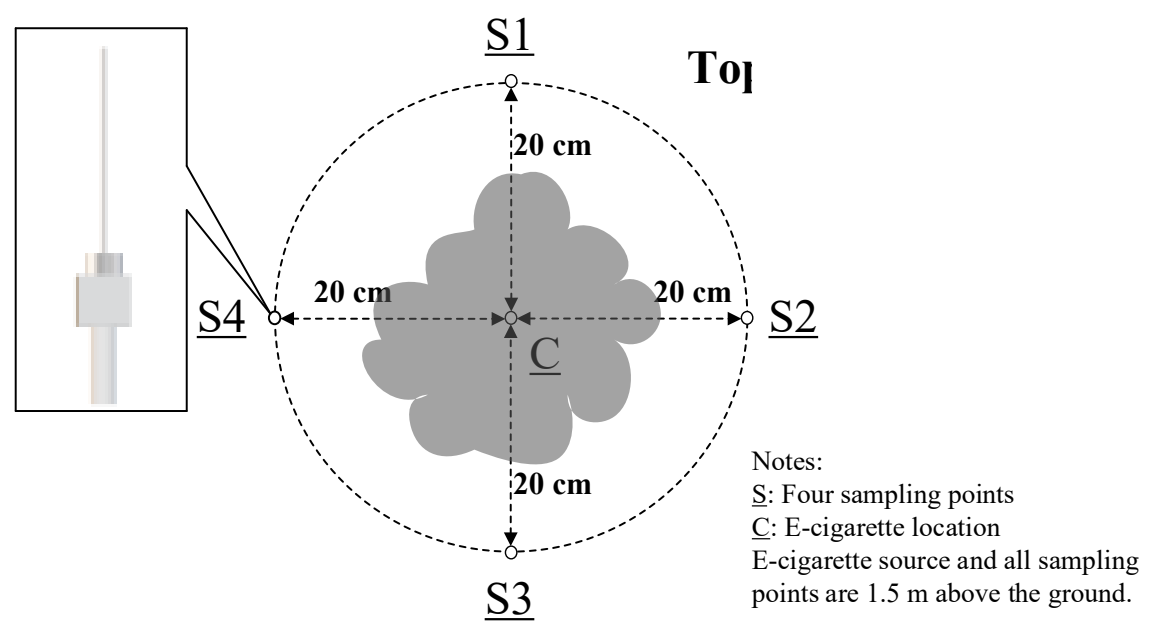

Fig. 3. Experimental setup for secondhand aerosol sampling using needle trap samplers and SPME fiber.

chromatography (GC; 6890N)-mass spectroscopy (MS; 5973) system (Agilent Technologies, Inc., Wilmington, DE, USA). The GC capillary column was HP 19091Z-413 HP-1 PDMS (30 $\mathrm{m} \times 320 \mu \mathrm{m}$ $\times 0.25 \mu \mathrm{m}$; Agilent Technologies, Inc.). All gases (Jing De Gases Co., Ltd., Kaohsiung, Taiwan) that were used in GC-MS analysis were of ultra-high purity, and the standard chemicals (Merck, Darmstadt, Germany) in the quantification analysis were of analytic grade.

After gas sampling, the NTS and $100 \mu \mathrm{m}$ PDMS SPME fibers (Supelco) were taken to the laboratory and then inserted into the injection ports of the GC for analysis. The desorption time and temperature at the injection port were $30 \mathrm{~s}$ and $250^{\circ} \mathrm{C}$, respectively. The temperature of the $\mathrm{GC}$ was increased from $50^{\circ} \mathrm{C}$ in increments of $15^{\circ} \mathrm{C} \mathrm{min}^{-1}$ to $180^{\circ} \mathrm{C}$, which was held for $2 \mathrm{~min}$. The flow rate of the carrier gas, helium, was $1.8 \mathrm{~mL} \mathrm{~min}^{-1}$. Notably, based on earlier examinations by Cheng et al. $(2011,2013)$, who used NTS analytical procedures, no carryovers were available when NTS samples were thermally desorbed at the GC inlet ports.

The calibration analysis for organic compounds extracted by NTS was carried out in the laboratory using the Tedlar bag of $1 \mathrm{~L}$. The laboratory assistant injected the liquid target chemical of $0.05 \mu \mathrm{L}$ into a Tedlar bag, which is filled with $1 \mathrm{~L}$ zero air in advance, using a microsyringe, and then put the bag in the oven under $27^{\circ} \mathrm{C}$. After $1 \mathrm{~h}$, the compound is completely evaporated and the concentration of the compound in the bag is $C_{1}\left(\mathrm{mg} \mathrm{m}^{-3}\right)$. Finally, the sampling pump of the same specifications as that which was installed for e-cigarette sampling was used to connect the NTS and the bag in an active sampling mode. Because the Tedlar bag is compressible, the volume of bag is reduced during the exhausting period; however, the concentration of the target compound in the Tedlar bag remains the same. When the sampling time is $1 \mathrm{~min}$, and the GC-MS integral analysis area of the NTS is $A_{1}$, the concentration $C_{2}\left(\mathrm{mg} \mathrm{m}^{-3}\right)$ of the target compound sampled by the NTS in the smoke of an e-cigarette is calculated as:

$C_{2}=\left[\left(\frac{A_{2}}{A_{1}}\right) \times \frac{1}{t}\right] \times C_{2}$

where $A_{2}$ is the GC-MS integral analysis area of NTS taking a sample from the smoke of an $\mathrm{e}$-cigarette; and $t$ is the sampling time for the smoke of an e-cigarette. For example, nicotine sampled by an NTS was examined with an integral area of 2,995,604 using the GC-MS analysis, and the NTS sampling time was $15 \mathrm{~s}(0.25 \mathrm{~min})$. The standard concentration of gaseous nicotine prepared in the 1-L Tedlar bag is $252.5 \mathrm{mg} \mathrm{m}^{-3}$ and the analysis area by the GC-MS was $13,055,422$. Substituting the data into Eq. (2), the concentration of triacetin was calculated as $(2,995,604 / 13,055,422) \times(1 / 0.25) \times 252.5=231.7 \mathrm{mg} \mathrm{m}^{-3}$.

For an SPME analysis calibration, the laboratory assistant prepared chemicals of given concentrations in a 550-mL glass bulb, and then an SPME fiber was used to adsorb the gas sample from the bulb for analysis using the GC-MS. The integral area was obtained for the given 
concentrations of specific compounds. The concentrations of compounds sampled from the smoke of an e-cigarette were also determined based on the proportional calculation using Eq. (2).

\section{RESULTS AND DISCUSSIONS}

\subsection{Chemical Constituents of E-cigarette Aerosol}

Fig. 4 presents variations of the GC-MS analysis area of chemical compounds in e-cigarette aerosol with puffs based on the 19 samplings by NTS. Notably, a leakage of e-liquid resulted in extremely high concentrations of airborne chemicals in Puff \#8, for which the GC-MS analysis area was about 3-7 times those for non-leakage puffs. E-liquid sometimes leaks when users puff an e-cigarette and they then expose themselves to concentrations of chemicals, including a nicotine concentration of $914 \mathrm{mg} \mathrm{m}^{-3}$. Users must avoid the unexpected leakage of e-liquid from poor filters of e-cigarettes to prevent exposures to high concentrations.

Except in cases of leakage, airborne VG $\left(2,904 \pm 1,015 \mathrm{mg} \mathrm{m}^{-3}\right)$ and PG $\left(2,605 \pm 1,211 \mathrm{mg} \mathrm{m}^{-3}\right)$, which are the base constituents of e-liquid, were the main chemical compounds in e-cigarette aerosol. VG and PG are generally used as food additives, which are not harmful to human health; however, frequent dermal exposure to PG sometimes irritates human skin (Agency for Toxic Substances and Disease Registry [ATSDR], 1997). Triacetin ( $88 \pm 98 \mathrm{mg} \mathrm{m}^{-3}$, except during the leakage) is a commonly used fixative for perfumes, and its concentrations are much lower than those of VG, PG and nicotine. The analysis areas of other components using GC-MS, including ethanol, ethyl ether, isoamyl acetate (vegetable flavor), ethyl maltol (flavor intensifier), ocimene (vegetable flavor), and decalactone (flavor intensifier), are less than $1 \%$ of that for VG (Fig. 4).

Notably, nicotine (146 $\pm 51 \mathrm{mg} \mathrm{m}^{-3}$, except in the leakage case) is a neurotransmission stimulant which stimulates neurons in the sympathetic nervous system, increasing heart rate and blood pressure (Kent, 1998). The American Conference of Governmental Industrial Hygienists (ACGIH)regulated maximum time-weighted average threshold limit value (TLV-TWA) of human dermal exposure is $0.5 \mathrm{mg} \mathrm{m}^{-3}$ (ACGIH, 2009), but no legal limit on exposure in air though inhalation has been set. Korean workers at tobacco curing barns commonly have acute exposure to $610 \mathrm{mg} \mathrm{m}^{-3}$ nicotine (Yoo et al., 2014). In this work, a leakage of e-liquid from the filter of an e-cigarette cartridge resulted in exposure of users to a high concentration of airborne nicotine of $914 \mathrm{mg} \mathrm{m}^{-3}$ in the smoke. Such a leakage may be a sudden event and users always clean or dump the residual e-liquid on the filter before resuming puffing, but one leakage occurred in a puffing session herein.
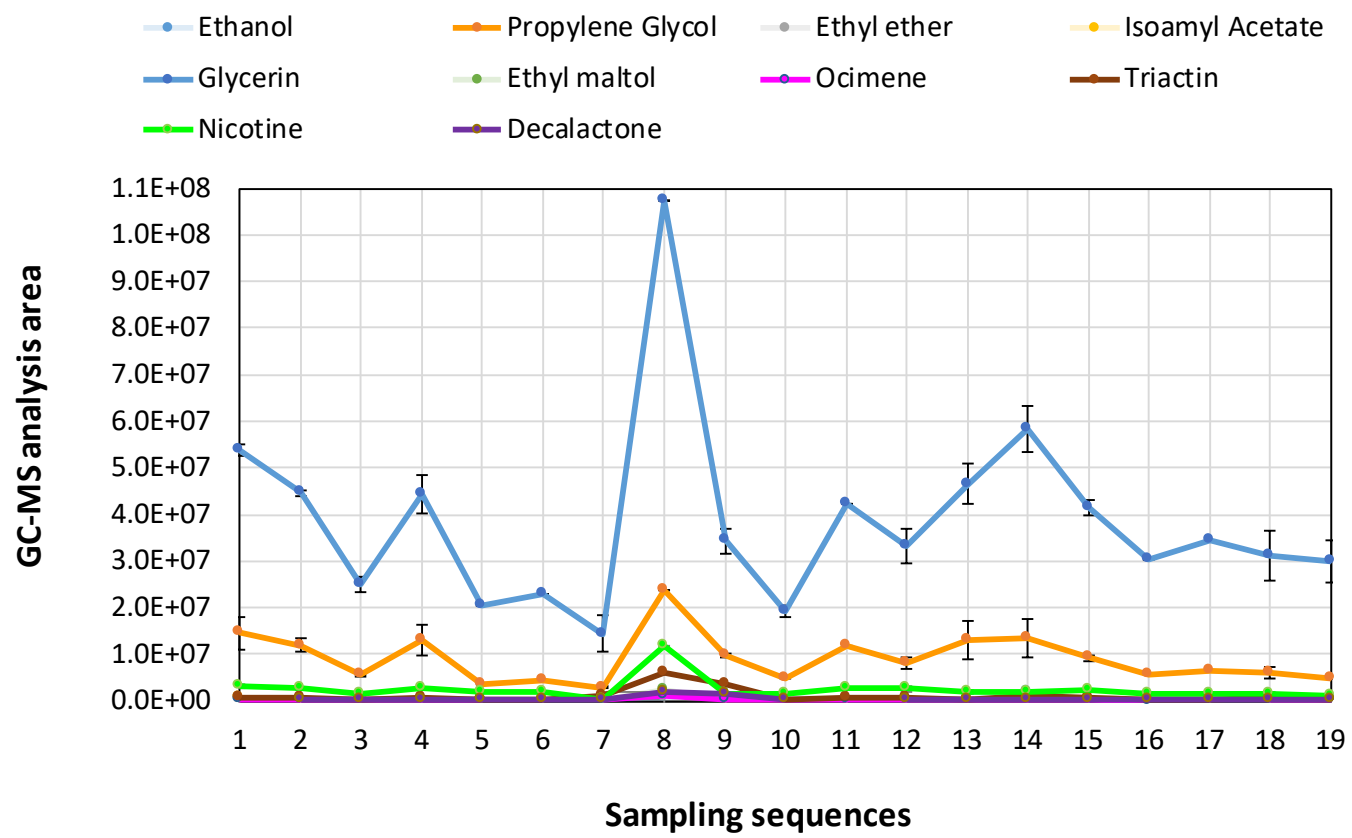

Fig. 4. Variations of chemical compounds with e-cigarette puffing sequence. 
A leakage of e-liquid must be avoided to prevent exposure to extremely high concentration of nicotine.

Lee et al. (2018) reported that the mean puffing volume of 6 non-established e-cigarette smokers was $55 \mathrm{~mL}$, while that for 14 established smokers was $110 \mathrm{~mL}$. Goniewicz et al. (2013) compared the mass of nicotine in aerosol that was released from 16 e-liquids in 150 puffs with that in aerosol and found values from 0.3 to $8.7 \mathrm{mg}$. From the puff volumes of non-established e-cigarette smokers and established e-cigarette smokers, 150 puffs, and the mean airborne nicotine concentration (except in the leakage case) of $146 \mathrm{mg} \mathrm{m}^{-3}$ in this study, the non-established ecigarette smokers are exposed to $1.2 \mathrm{mg}$ nicotine $\left(146 \mathrm{mg} \mathrm{m}^{-3} \times 55 \mathrm{~mL} \times 10^{-6} \mathrm{~m}^{3} \mathrm{~mL}^{-1} \times 150\right)$, and the established e-cigarette smokers are exposed to $2.4 \mathrm{mg}$ nicotine $\left(146 \mathrm{mg} \mathrm{m}^{-3} \times 110 \mathrm{~mL} \times 10^{-6}\right.$ $\left.\mathrm{m}^{3} \mathrm{~mL}^{-1} \times 150\right)$. The range of 1.2-2.4 $\mathrm{mg}$ nicotine exposures from e-liquids to smokers, based on the results of this assessment, is consistent with the findings of Goniewicz et al. $(0.3-8.7 \mathrm{mg}$ nicotine) in 2013.

\subsection{Simulation of Exposures to Nicotine in Secondhand Aerosol from \\ E-cigarettes}

The concentrations of main compounds of SPME samples at the corridor do not differ from those determined using the NTS in Table 1. This finding reveals that NTS is an alternative method for nicotine sampling. Notably, an NTS collected both particle-bound and free compounds; however, an SPME fiber mainly adsorbed gaseous compounds (Niri et al., 2009). The phenomenon that nicotine in the aerosol of e-cigarettes collected by an NTS $\left(1.74 \pm 0.44 \mathrm{mg} \mathrm{m}^{-3}\right)$ were higher than those collected by an SPME fiber $\left(1.38 \pm 0.70 \mathrm{mg} \mathrm{m}^{-3}\right)$ complied with Niri et al. (2009)'s finding.

Table 1 shows the TWA exposure concentrations of nicotine in secondhand aerosol from ecigarettes both outdoors (courtyard) and indoors (corridor). Concentrations of nicotine are lower in the courtyard than in the corridor. This difference may have arisen from the dilution in the air stream in the windy courtyard. Gusts of around 5-10 $\mathrm{m} \mathrm{s}^{-1}$ occurred in the courtyard on the sampling day, whereas the corridor was almost windless. According to the NTS analysis data in Table 1, which were collected in the courtyard and corridor, the differences between the concentration of other compounds in the aerosols of the e-cigarette also follow the trend exhibited by those of nicotine. The concentrations of the main compounds in secondhand aerosol from e-cigarettes (nicotine, VG, PG, and triacetin) are much lower than those in aerosols from the heated e-liquid to which users are exposed.

\section{CONCLUSIONS}

We successfully extracted and analyzed chemical compounds from e-cigarette aerosol using NTSs, which were packed with 60-80-mesh DVB adsorbent, and a GC-MS system, respectively. These NTSs were fabricated in the laboratory, and the adsorbents were selected based on their

Table 1. Concentrations of main compounds in the secondhand aerosols by different sampling methods.

\begin{tabular}{llll}
\hline \multirow{2}{*}{ Compounds } & \multicolumn{2}{l}{ Sampling methods and concentrations $\left(\mathrm{mg} \mathrm{m}^{-3}\right)^{(1)}$} \\
\cline { 2 - 4 } & & $\mathrm{NTS}^{(2)}$ & $\mathrm{SPME}^{(2)}$ \\
\hline Corridor & Nicotine & $1.74 \pm 0.44$ & $1.38 \pm 0.70$ \\
& Vegetable Glycerin & $38.7 \pm 18.4$ & $36.7 \pm 15.0$ \\
& Propylene Glycol & $9.56 \pm 4.86$ & $8.16 \pm 1.86$ \\
& Triacetin & $2.69 \pm 1.31$ & $2.29 \pm 1.11$ \\
Courtyard & Nicotine & $0.43 \pm 0.21$ & - \\
& Vegetable Glycerin & $12.0 \pm 6.0$ & - \\
& Propylene Glycol & $4.06 \pm 1.96$ & - \\
& Triacetin & $0.83 \pm 0.35$ & - \\
\hline
\end{tabular}

${ }^{(1)}$ Concentrations are displayed as (means \pm standard deviations).

(2) The sampling numbers of NTS were four for the courtyard and five for the corridor. The SPME samplings were performed only at the corridor and the sampling number was five. 
affinity with the compounds. Notably, the cost of manufacturing is far lower for an NTS (which consists of a needle and adsorbents)-only approximately USD 10-than a commercial SPME fiber (USD 65) and its holder (USD 200).

According to our results, e-cigarette users are exposed to high levels of nicotine (146 \pm $51 \mathrm{mg} \mathrm{m}^{-3}$ ). If e-liquid leaks through the filter of the cartridge, the exposure concentrations may even reach $914 \mathrm{mg} \mathrm{m}^{-3}$. Therefore, an e-cigarette is not a perfect tool for smoking cessation.

Finally, we found significantly lower concentrations of the analyzed compounds in the secondhand than the firsthand smoke. For example, the level of nicotine (which ranged from approximately 0.43 to $1.74 \mathrm{mg} \mathrm{m}^{-3}$ ) averaged less than $1 \mathrm{mg} \mathrm{m}^{-3}$. However, the risks of nicotine exposure via secondhand e-cigarette aerosol must be evaluated in greater detail in the future.

\section{ACKNOWLEDGEMENT}

Authors would like to thank Mr. Wei-Chih Chen for providing experimental materials and recommendations.

\section{DISCLAIMER}

The authors declare no conflict of interest.

\section{REFERENCES}

Agency for Toxic Substances and Disease Registry (ATSDR) (1997). ToxFAQs- propylene glycol, Atlanta, GA.

American Conference of Governmental Industrial Hygienists' (ACGIH) (2009). Threshold Limit Values (TLVs) for Chemical Substances and Physical, Cincinnati, Ohio.

Cheah, N.P., Chong, N.W., Tan, J., Morsed, F.A., Yee, S.K. (2012). Electronic nicotine delivery systems: regulatory and safety challenges: Singapore perspective. Tob. Control. 23, 119-125. https://doi.org/10.1136/tobaccocontrol-2012-050483

Cheng, W.H., Zhan, W., Pawliszyn, J. (2011). Extraction of gaseous VOCs using passive needle trap samplers. Aerosol Air Qual. Res. 11, 387-392. https://doi.org/10.4209/aaqr.2011.01.0001

Cheng, W.H., Zhan, W., Pawliszyn, J. (2013). Gaseous and particle-bound VOC products of combustion extracted by needle trap samplers. J. Chin. Chem. Soc. 60, 1027-1032. https://doi.org/10.1002/jccs.201200654

Cheng, W.H., Huang, H.L., Cheng, K.S., Chang, Y.C. (2017). Quantification of VOC emissions from paint spraying on a construction site using solid phase microextraction devices. J. Environ. Sci. Health A 52, 1158-1163. https://doi.org/10.1080/10934529.2017.1356208

Cheng, W.H., Wu, H.M. (2019). Assessing organic chemical emissions and workers' risk of exposure in a medical examination center using solid phase microextraction devices. Aerosol Air Qual. Res. 19, 865-870. https://doi.org/10.4209/aaqr.2018.08.0288

Cheng, W.H., Huang, H.L., Chuang, M.H. (2020). Use of passive SPME sampling devices to determine exposure of oil painters to organic compounds. J. Air Waste Manag. Assoc. 70, 253259. https://doi.org/10.1080/10962247.2019.1694090

DeVito, E.E., Krishnan-Sarin, S. (2018). E-cigarettes: Impact of E-liquid components and device characteristics on nicotine exposure. Curr. Neuropharmacol. 16, 438-459. https://doi.org/10. 2174/1570159X15666171016164430

Farsalinos, K.E., Yannovits, N., Sarri, T., Voudris, V., Poulas, K. (2018). Nicotine delivery to the aerosol of a heat-not-burn tobacco product: comparison with a tobacco cigarette and e-cigarettes. Nicotine Tob. Res. 20, 1004-1009. https://doi.org/10.1093/ntr/ntx138

Goniewicz, M.L., Kuma, T., Gawron, M., Knysak, J., Kosmider, L. (2013). Nicotine levels in electronic cigarettes. Nicotine Tob. Res. 15, 158-166. https://doi.org/10.1093/ntr/nts103

Hadwiger, M.E., Trehy, M.L., Ye, W., Moore, T., Allgire, J., Westenberger, B. (2010). Identification of amino-tadalafil and rimonabant in electronic cigarette products using high pressure liquid chromatography with diode array and tandem mass spectrometric detection. J. Chromatogr. 
A 1217, 7547-7555. https://doi.org/10.1016/j.chroma.2010.10.018

Kent, C. (1998). Basics of Toxicology. John Wiley \& sons, Inc., New York, NY, pp. 135-136.

Kim, Y.H., An, Y.J. (2020). Development of a standardized new cigarette smoke generating (SNCSG) system for the assessment of chemicals in the smoke of new cigarette types (heat-not-burn (HNB) tobacco and electronic cigarettes (E-Cigs)). Environ. Res. 185, 109413. https://doi.org/ 10.1016/j.envres.2020.109413

Kosmider, L., Jackson, A., Leigh, N., O’Connor, R., Goniewicz, M.L. (2018). Circadian puffing behavior and topography among e-cigarette users. Tob. Regul. Sci. 4, 41-49. https://doi.org/1 $0.18001 /$ TRS.4.5.4

Lee, Y.O., Nonnemaker, J.M., Bradfield, B., Hensel, E.C., Robinson, R.J. (2018). Examining daily electronic cigarette puff topography among established and nonestablished cigarette smokers in their natural environment. Nicotine Tob. Res. 20, 1283-1288. https://doi.org/10.1093/ntr/n tx222

Lee, Y.O., Morgan-Lopez, A.A., Nonnemaker, J.M., Pepper, J.K., Hensel, E.C., Robinson, R.J. (2019). Latent class analysis of e-cigarette use sessions in their natural environments. Nicotine Tob. Res. 21, 1408-1413. https://doi.org/10.1093/ntr/nty164

Lord, H., Zhan, W., Pawliszyn, J. (2010). Fundamentals and applications of needle trap devices. Anal. Chim. Acta 677, 3-18. https://doi.org/10.1016/j.aca.2010.06.020

Niri, V.H., Eom, I.Y., Kermani, F.R., Pawliszyn, J. (2009). Sampling free and particle-bound chemicals using solid-phase microextraction and needle trap device simultaneously. J. Sep. Sci. 32, 1075-1080. https://doi.org/10.1002/jssc.200800603

Pisinger, C., Døssing, M. (2014). A systematic review of health effects of electronic cigarettes. Prev. Med. 69, 248-260. https://doi.org/10.1002/jssc.200800603

Schober, W., Szendrei, K., Matzen, W., Osiander-Fuchs, H., Heitmann, D., Schettgen, T., Jörres, R.A., Fromme, H. (2014). Use of electronic cigarettes (e-cigarettes) impairs indoor air quality and increases FeNO levels of e-cigarette consumers. Int. J. Hyg. Environ. Heal. 217, 628-637. https://doi.org/10.1016/j.ijheh.2013.11.003

Shearston, J., Lee, L., Eazor, J., Meherally, S., Park, S.H., Vilcassim, M.J.R., Weitzman, M., Gordon, M. (2019). Effects of exposure to direct and secondhand hookah and e-cigarette aerosols on ambient air quality and cardiopulmonary health in adults and children: Protocol for a panel study. BMJ Open 9, e029490. https://doi.org/10.1136/bmjopen-2019-029490

Wu, W., Ashley, D.L., Watson, C.H. (2002). Determination of nicotine and other minor alkaloids in international cigarettes by solid-phase microextraction and gas chromatography/mass spectrometry. Anal. Chem. 74, 4878-4884. https://doi.org/10.1021/ac020291p

Yang, S.S., Smetena, I. (1998). Determination of tobacco alkaloids using solid phase microextraction and GC-NPD. Chromatographia 47, 443-448. https://doi.org/10.1007/BF02466477

Yoo, S.J., Park, S.J., Kim, B.S., Lee, K., Lim, H.S., Kim, J.S., Kim, I.S. (2014). Airborne nicotine concentrations in the workplaces of tobacco farmers. J. Prev. Med. Public Health 47, 144-149. https://doi.org/10.3961/jpmph.2014.47.3.144 